\title{
LICENÇA-MATERNIDADE E ESTABILIDADE DA GESTANTE PARA HOMENS
}

\author{
MATERNITY LEAVE AND STABILITY FOR \\ PREGNANT WOMEN
}

\author{
Assis Moreira Silva Junior \\ Luis Fernando Severino
}

\section{RESUMO}

Neste artigo são tratados casos em que o modelo de proteção exige alterações pontuais em relação aos personagens, garantindo-se o direito à estabilidade da gestante e à licença-maternidade não apenas à mulher, mas também ao homem, em alguns casos excepcionais, quais sejam, viúvo cujo falecimento da esposa tenha se dado por complicações decorrentes do parto, genitor solteiro, casal homoafetivo e genitor ou futuro genitor que seja o único provedor da renda familiar. Há necessidade de compatibilização entre as matérias normativas de diferentes disciplinas, com alterações legislativas que aumentem a proteção, com especial atenção para a entidade familiar, que goza de especial proteção do Estado. Mas isso não impede o gozo de tais direitos para os casos excepcionais mencionados, tendo em vista a interpretação sistemática do texto constitucional.

Palavras-chave: Estabilidade. Homens. Filhos.

\begin{abstract}
This article deals with cases where the protection model requires specific changes in relation to the characters, ensuring the right to pregnancy stability and maternity leave, not only to women but also to men, in some exceptional cases that we discussed about, as a widower whose
\end{abstract}


wife's death has been given from complications through childbirth, single parent, homosexual couple and future parent who is the unique provider of the family income. There is need for compatibility between the normative subjects from different disciplines, with legislative changes that increase the protective mantle, with special attention to the family entity, which enjoys special protection by the State. But this does not prevent the enjoyment of such rights to the exceptional cases mentioned, in view of the systematic interpretation of the constitutional text.

Keywords: Stability. Men. Children.

\section{INTRODUÇÃO}

O que mais se encontra no ordenamento jurídico são termos (ou preceitos normativos) que ligam a maternidade à figura da mulher, o que é natural, afinal são elas dotadas do dom da gestação: afastamento maternidade para a mulher, descanso legal à mulher gestante, estabilidade para a mulher gestante, dentre tantos outros. Houve o escopo inicial de proteger a mulher empregada, de modo a promover a maternidade de forma segura, com a garantia de que seu emprego fosse mantido por um determinado período. A doutrina assevera que a garantia do salário-maternidade veio inicialmente no ordenamento brasileiro como uma forma de proteger o trabalho feminino, ${ }^{1}$ num momento em que a família dita tradicional era composta pela união entre homem e mulher, e os filhos, biológicos ou adotados. O próprio Código Civil de 2002 (CC) ainda traz estampada tal ideia. ${ }^{2}$

Destaque-se a existência de normas voltadas a eliminar a discriminação da mulher no mercado de trabalho, mesmo porque, antes da incorporação da Convenção 103 da Organização Internacional do Trabalho (OIT), ${ }^{3}$ era o art. 392 da Consolidação das Leis do Trabalho (CLT) que regulava a relação. Era do empregador a responsabilidade do custeamento contratual durante o período de afastamento, encarecendo o contrato de emprego da mulher, o que reduzia - na verdade dificultava - sua competitividade no mercado de trabalho em igualdade com o homem, fato também configurador de discriminação.

Percebe-se, pois, que sempre houve correlação exclusiva entre a mulher e a maternidade, evidentemente, e também, pelo aspecto bio- 
lógico. A própria legislação desenvolvida a partir do início do século passado visava a assegurar igualdade material - com a desigualdade jurídica - entre homens e mulheres, levando-se em conta suas peculiaridades físicas, com especificidade para a maternidade.

Houve, porém, uma alteração importante quanto à necessidade de normas diferenciadoras entre homens e mulheres. O cenário de mudanças não passa apenas pela retirada ou não das normas de proteção da mulher, mas também por mudanças conceituais e contextuais, acompanhando o dinamismo social que modifica, cria e desenvolve inúmeras possibilidades de relações e situações.

Interessante repensar e verificar, em relação ao sujeito da proteção jurídica na maternidade, se a mulher e a criança merecem proteção jurídica conjunta, se é possível pensar em maternidade de forma independente - em certas situações e momentos - da figura da mulher, e dependente - nessas situações e momentos - da figura do nascituro.

Considerando que a maternidade não está ligada exclusivamente à figura da mulher, mas, sim, à figura de quem a exerce, ela pode ser exercida pela mulher ou pelo homem. Nas hipóteses de viúvo cujo falecimento da esposa tenha se dado por complicações decorrentes do parto, ${ }^{4}$ de genitor solteiro, de casal homoafetivo e de genitor ou futuro genitor que seja o único provedor da renda familiar, observa-se, de forma mais evidenciada, que a proteção se dá em relação aos filhos e à família em si, independentemente da idade da criança, tendo em vista a necessidade de acompanhamento pelo(s) genitor(es) para incluí-la na unidade familiar, além de garantir seu desenvolvimento pleno e saudável.

O presente trabalho analisa as hipóteses em que a licença-maternidade e a estabilidade da gestante devem ser estendidas aos genitores homens. Para tal empreitada, como método, adota-se a pesquisa bibliográfica que versa sobre as questões relativas ao assunto proposto. $\mathrm{O}$ desenvolvimento do trabalho dá-se com a leitura analítica de algumas das principais publicações existentes sobre Direito do Trabalho.

Quanto ao aspecto estrutural, oportuno registrar que o presente trabalho subdivide-se em seis tópicos, nos quais os assuntos suscitados, relevantes para uma reflexão satisfatória da temática indicada, são apresentados de forma sistematizada, almejando demonstrar o engendramento dos conteúdos listados. 
Inicialmente discorre-se sobre os fundamentos que justificam o entendimento de que a licença-maternidade e a estabilidade da gestante não estão ligadas apenas à figura da mulher, mas principalmente à figura da criança. Antes do tópico central do trabalho, analisam-se a evolução do conceito de família e a atividade legislativa recente sobre o tema, cuja análise mostrou-se necessária para o desenvolvimento do quinto tópico, em que se analisa a possibilidade jurídica da concessão da licença-maternidade e da estabilidade da gestante para os homens. No último tópico, antes das conclusões finais, aborda-se, ainda que brevemente, a tutela de direitos.

\section{PANORAMA DO ORDENAMENTO JURÍDICO BRASILEIRO}

Observa-se uma grande preocupação com a proteção à maternidade, na medida em que uma das primeiras convenções adotadas pela OIT, apenas quatro meses após a sua criação pelo Tratado de Versalhes no ano de 1919, disciplinou o tema, ${ }^{5}$ estabelecendo a proibição do trabalho da mulher no período de seis semanas após o parto, com o recebimento de uma indenização durante o referido período.

Essa Convenção foi revista pela OIT no ano de 1952, o que culminou na edição da Convenção n. ${ }^{\circ}$ 103, ratificada pelo Brasil em 18 de junho de 1965 e promulgada pelo Decreto n. ${ }^{\circ} 58.820$, de 14 de julho de 1966. Embora revista, essa convenção, os princípios básicos não sofreram alterações, mas seu alcance se fez maior e as disposições relativas às vantagens foram ampliadas, com a previsão de licença-maternidade com duração mínima de 12 semanas, com direito a prestações em espécie durante o período de afastamento, concedidas nos moldes de um seguro obrigatório, tendo vedada a imputação do seu custo ao empregador.

No Brasil, a primeira disposição a prever o referido direito foi o Decreto n. ${ }^{\circ}$ 21.417-A, de 17 de maio de 1932, que versou sobre a situação da mulher trabalhadora e estabeleceu o descanso de quatro semanas antes e quatro semanas depois do parto, com a percepção de metade do salário.

A Consolidação das Leis do Trabalho (CLT), promulgada pelo Decreto-Lei n. ${ }^{\circ}$ 5.452, de $1^{\circ}$ de maio de 1943 , ao disciplinar o assunto, 
em seu art. 392, em sua redação original, previa a proibição do trabalho da mulher grávida no período de seis semanas antes e seis semanas após o parto. Posteriormente, no ano de 1967, a referida disposição foi alterada para proibir o trabalho no período de quatro semanas antes e oito semanas após o parto, não tendo sido modificado o período total de afastamento do serviço, que correspondia a 84 dias.

Com a promulgação da Constituição Federal de 1988 (CF/88), o referido prazo foi ampliado para 120 dias, nos termos do inciso XVIII do art. $7^{\circ}$. Inicialmente, ficou a cargo do empregador o pagamento do período acrescido pela $\mathrm{CF} / 88,{ }^{6}$ o que não se dá nos dias atuais, já que é assegurado o pagamento de benefício previdenciário consistente no salário-maternidade, no valor da remuneração integral da empregada. ${ }^{7}$

Havia entendimento jurisprudencial que considerava o direito à licença-maternidade apenas à mãe biológica, tendo como finalidade precípua proteger a saúde da mãe do recém-nascido, conforme se observa em julgado do Supremo Tribunal Federal (STF) que assinalou:

No caso em exame, o direito à licença é vinculado ao fato jurídico gestação, que não permite, segundo penso, a extensão do benefício à hipótese do ato de adoção. Fosse a referência constitucional, por exemplo, simplesmente a 'mãe' ou a 'maternidade', poder-se-ia, ainda, cogitar de assimilação da adotante à gestante. Não, porém, segundo penso, quando especificada a primeira na norma aplicável (STF, $1^{\text {a }}$ Turma, RE 197.807-4/RS, Rel. Min. Octávio Gallotti, j. 30.05.2000, DJ 18.08.2000).

Esse posicionamento desnudava de proteção jurídica ampla e irrestrita os filhos adotados, ocasionando desigualdade arbitrária, sem qualquer justificativa sustentável de base. Houve alteração normativa - de acordo com o princípio constitucional da isonomia, e que pode também justificar o debate acerca do corte umbilical entre a genitora e seu filho com relação à maternidade - para prever o direito ao salário-maternidade também para os casos de adoção e de obtenção de guarda judicial para fins de adoção, trazidos pela Lei n. ${ }^{\circ} 10.421 / 02$, que inseriu o art. 71-A à Lei n. ${ }^{\circ} 8.213 / 91$, assim como o art. 392-A na CLT, porém, ainda assim ligada exclusivamente à figura da mulher. ${ }^{8}$

No julgamento do RE n. ${ }^{\circ}$ 197.807-RS, acima mencionado, a Procuradoria-Geral da República assinalou que não apenas a mãe estaria 
protegida pela licença-maternidade, a qual confere igualmente proteção à criança, à família e ao próprio trabalho da mulher.

Como assinalado por Bossa (1998, p. 6), “As normas protetoras da maternidade visam garantir melhores condições de cuidar da gravidez, do parto e da primeira infância, dada a importância desses processos para a vida da mãe e da criança".

Com relação à licença-maternidade adotiva, importante assinalar que ela fora inicialmente escalonada, a depender da idade da criança (quanto mais jovem a criança, maior era o prazo da licença), o que foi alterado pela Lei n. ${ }^{\circ}$ 12.010/2009 (lei da adoção), que revogou os parágrafos $1^{\circ}, 2^{\circ}$ e $3^{\circ}$ do art. 392-A da CLT, equiparando as duas hipóteses de licença. A justificativa para uma licença-maternidade com prazo de 120 dias, no caso de adoção, reside na necessidade de manter um maior contato com a criança que fora adotada, de modo a estabelecer o vínculo afetivo e inseri-la em sua nova família. ${ }^{9}$

Ainda vale destacar que, em 9 de setembro de 2008, foi publicada a Lei n. ${ }^{\circ} 11.770$, a qual permite a ampliação facultativa do período de licença-maternidade em 60 dias, cujo objetivo é proporcionar à mãe contato direto com a criança por mais tempo, facilitando até mesmo o aleitamento materno, motivo pelo qual, durante o período de prorrogação, a empregada não poderá exercer qualquer atividade remunerada e a criança não poderá ser mantida em creche ou organização similar.

Não há dúvida, portanto, de que filhos biológicos e adotados devem receber o mesmo tratamento jurídico-constitucional e infraconstitucional. Inclusive, recente decisão - estampada no próprio sítio da Previdência Social ${ }^{10}$ - passou a garantir às mães de filhos biológicos e adotados, independentemente da idade, o mesmo prazo de 120 dias de licença-maternidade, desde que preenchidos os demais requisitos legais. Destaque-se um dos principais pilares da decisão em tela:

É certo que a Constituição Federal tutela somente a licença à gestante, sendo o direito à adotante estendido por opção legislativa. Todavia, tal argumento não é capaz de afastar a discriminação inconstitucional que foi conferida aos filhos adotados. Por outro lado, não vislumbro razoabilidade no argumento de que as razões de diferenciação são a ausência de necessidade de recuperação da saúde da mulher e o fato 
de que as crianças maiores de um ano não dependem de amamentação. É que uma criança adotada precisa de um período de aclimatação e adaptação à nova família, sendo indispensável a presença do pai, mãe ou responsável nos primeiros meses de adoção. $O$ sucesso da adoção dependerá do total acolhimento e atenção dada pela mãe ao seu novo filho. Para isso, é preciso tempo e dinheiro. Assim, ao não conceder tempo e recursos para que seja perfectibilizada tal adaptação, o Estado está a desestimular a prática da adoção, sabendo que existem muitas crianças maiores de um ano de idade que precisam de proteção e atenção para sair das ruas e se tornarem cidadãs (grifo nosso).

Com relação à figura da adoção, a CF/ 88 assim consagra em seu art. $227, \S \S 5^{\circ}$ e $6^{\circ}$ :

Art. 227. É dever da família, da sociedade e do Estado assegurar à criança, ao adolescente e ao jovem, com absoluta prioridade, o direito à vida, à saúde, à alimentação, à educação, ao lazer, à profissionalização, à cultura, à dignidade, ao respeito, à liberdade e à convivência familiar e comunitária, além de colocá-los a salvo de toda a forma de negligência, discriminação, exploração, violência, crueldade e opressão. [...]

$\S 5^{\circ} \mathrm{A}$ adoção será assistida pelo Poder Público, na forma da lei, que estabelecerá casos e condições de sua efetivação por parte de estrangeiros.

$\S 6^{\circ}$ Os filhos, havidos ou não da relação do casamento, ou por adoção, terão os mesmo direitos e qualificações, proibidas quaisquer designações discriminatórias relativas à filiação (grifo nosso).

O Tribunal Superior do Trabalho (TST) se manifestou recentemente sobre a proteção especial à vida do nascituro - restando, agora, dar a mesma proteção às crianças adotadas:

Tem-se por incabível exegese restritiva de norma constitucional que garante, de forma ampla, às empregadas gestantes a manutenção do emprego e a respectiva licença, quando o bem tutelado, em última análise, é a própria vida do nascituro. Apesar de a gravidez não ser patologia, trabalhadora grávida ostenta a mesma fragilidade laboral que se evidencia nos empregados acometidos por doença, sendo mínimas as chances de obter novo emprego enquanto perdurar o estado gravídico e o período de amamentação inicial - que, não por acaso, coincide com o tempo da garantia de emprego (TST, SBDI-I, E-ED-RR 
249100-26.2007.5.12.0004, Rel. Min. Horácio Raymundo de Senna Pires, DEJT 09.04.2010, grifo nosso).

São várias as provas que evidenciam a postura protetora dos filhos e da família em si, não mais limitando o manto protetor apenas à relação mãe e filho. Não se deve esquecer de que a proteção à família deve ser especial por parte do Estado.

Pelo exposto, depreende-se que o direito social fundamental à licença-maternidade não se destina única e exclusivamente à proteção da mãe, mas também - e principalmente - à proteção da própria criança, que necessita de cuidados especiais na chamada primeira infância, a exemplo da amamentação, ou então necessita de atenção especial que viabilize sua inserção na família adotiva, o que independente da idade da criança adotada. Cuidados que também podem ser realizados pelo homem nas situações excepcionais tratadas.

\section{DO SISTEMA PATRIARCAL À PLURALIDADE DE FORMAS DE FAMÍLIA}

Durante muito tempo o homem foi considerado, em todos os aspectos, o chefe da família. Ele representava o sistema todo em qualquer situação religiosa, política e econômica, inclusive administrando seus membros, bem como a esposa. ${ }^{11}$

Havia uma visão da família como sendo um núcleo de procriação, o que acabou sofrendo, especialmente a partir do século passado, profunda alteração, pois a família passou a ser vista como uma forma de união pautada nas relações de afetividade, na busca da felicidade, do desenvolvimento pessoal e social de seus integrantes. Não há mais espaço para um membro - no caso o homem - administrar todo o sistema com ideias e decisões unilaterais. Evidente que houve alteração de seus valores estruturantes, principalmente pelo fato de que os próprios valores basilares da sociedade vêm sofrendo alterações, mutações.

Na visão de Luhmann (1980), a família pode ser considerada como um organismo formado por sistemas integrados - que são seus membros. Trata-se de um sistema ordenado, coordenado num primeiro momento pelos genitores. A gravidez é um evento que reflete em todo o organis- 
mo, atingindo a todos os sistemas, causando apreensão, modificação, participação geral e ativa. Na visão considerada comum, a mulher é o sistema de atuação diferenciada em relação aos demais, com o homem atuando de forma auxiliadora, porém ativa, durante o processo gestacional. Contudo, essa participação diferencial pode ser exercida em alguns momentos somente pelo homem - nos casos de falecimento da genitora em razão de complicações decorrentes do parto, de família monoparental masculina, de entidade familiar homoafetiva masculina e de genitor ou futuro genitor que seja o único provedor da entidade familiar.

A participação diferenciada e mais ativa que a conferida aos demais membros familiares está em sintonia com os cuidados iniciais e vitais que a criança necessita, não só em sua vinda mas em sua ida para o resto de sua vida. Tanto pelo conceito de entidade familiar de forma sistemática quanto pelo motivo do fundamento da decisão judicial que passou a garantir o mesmo prazo de salário-maternidade para filhos biológicos, adotados e mencionados linhas atrás, é possível perceber que a principal preocupação e fim é a proteção dos filhos, tanto no aspecto de vulnerabilidade vital e de início de convívio e constituição familiar quanto no aspecto de vulnerabilidade social.

O homem moderno apresenta como característica mais participação no processo de criação dos filhos, na satisfação das próprias obrigações do lar, dividindo e até assumindo o papel que antes, pelo modelo social imposto, era de exclusividade da mulher. A mulher moderna atua não mais exclusivamente nos afazeres do lar, assumindo o papel de provedora, no mínimo, de forma igual ao homem. ${ }^{12}$

Com as mudanças dos modelos familiares, ou melhor, com o aumento dos modelos familiares, diversificando seus membros, fica mais evidente que a própria maternidade pode - e em certos casos deve - ser exercida pelo homem, sozinho ou em conjunto com a mulher. Isso se observa nas famílias monoparentais masculinas (aquelas formadas exclusivamente pelo genitor e sua prole, consoante previsão expressa do $\S 4^{\circ}$ do art. 226 da CF/88), quando há o falecimento da genitora em razão de complicações decorrentes do parto e nas uniões homoafetivas masculinas.

Trata-se a família, então, como um sistema organizado e formado por seus membros. Também se menciona a ocorrência da pluralidade 
dos modelos familiares, portanto, com a possibilidade de esse sistema organizado se formar pela junção de diversos subsistemas, mas sempre mantendo a característica principal de ser o pilar estruturante da sociedade, uma de suas instituições ordenadoras fundantes mais importantes, na medida em que atua como formadora basilar educacional, intelectual e valorativa de seus membros.

O conceito de família que se tinha até recentemente se baseava no sistema patriarcal, segundo o qual a família se constituía exclusivamente por meio do matrimônio, tido este como o vínculo indissolúvel entre um homem e uma mulher, com o fim de gerar filhos. Contudo, com o advento da CF/88, a qual consagrou o princípio da pluralidade das formas de família, tem-se que a essência da formação dos núcleos familiares passou a ser o afeto, e não mais a procriação da espécie, na medida em que cada vez mais a sociedade se pauta em princípios da igualdade de direitos, diversidade, solidariedade, efetividade, afetividade e tolerância.

O constituinte originário previu expressamente três formas de constituição do sistema familiar, quais sejam, aquele formado pelo matrimônio, o constituído da união estável e o composto por um dos genitores e sua prole - chamada família monoparental.

Mais recentemente, em 5-5-2011, o STF, no julgamento conjunto da ADI 4277 e ADPF 132, reconheceu o caráter de entidade familiar às uniões homoafetivas, cujo voto do relator ministro Ayres Brito assevera que:

Não havendo outra questão preliminar remanescente, passo ao voto que me cabe proferir quanto ao mérito da causa. E, desde logo, verbalizo que merecem guarida os pedidos formulados pelos requerentes de ambas as ações. Pedido de 'interpretação conforme à Constituição' do dispositivo legal impugnado (art. 1.723 do Código Civil), porquanto nela mesma, Constituição, é que se encontram as decisivas respostas para o tratamento jurídico a ser conferido às uniões homoafetivas que se caracterizem por sua durabilidade, conhecimento do público (não-clandestinidade, portanto) e continuidade, além do propósito ou verdadeiro anseio de constituição de uma família (grifo nosso).

Observa-se, então, uma alteração com relação ao modelo de caracterizar a união familiar, pelo reconhecimento e proteção jurídica 
da união estável, tendo o casamento deixado de ser a única forma legítima de estabelecimento dessa união, bem como pela previsão da família monoparental. A mudança mais profunda, contudo, é a ligada ao próprio tipo de união, que acompanhou as alterações dos tipos de relacionamento, não mais de exclusividade entre homens e mulheres (heteroafetivas), podendo acontecer entre dois homens ou duas mulheres (homoafetivas).

Portanto, o que mais interessa para o reconhecimento de uma entidade como familiar é o amor duradouro, o propósito ou verdadeiro anseio de constituir uma família. A decisão do STF é um "divisor de águas" em relação à extensão ampla e irrestrita de todos os direitos já assegurados e existentes para a entidade familiar dita tradicional aos demais arranjos familiares previstos no texto constitucional.

Direitos inerentes aos atos sucessórios - patrimoniais e previdenciários - já estão sendo assegurados de forma progressiva, embora ainda em alguns casos mediante dolorosas e dificílimas provas e exigências dos entes públicos, provocando situações vexatórias para quem postula tais direitos, como se a relação - de uma vida inteira, muitas vezes - se pautasse por atos e sentimentos clandestinos, diferentes dos casos ditos tradicionais - nos quais muitas vezes sequer amor há, ao contrário das uniões homoafetivas que, diante da sociedade ainda muito preconceituosa, no mínimo, deve estar pautada por grande amor e coragem.

Necessário que haja total e irrestrita compatibilidade entre as matérias previdenciárias e trabalhistas relacionadas com as questões em debate, o que ainda demandará mais ações por parte do Estado, conforme adiante se analisa.

\section{DA ATIVIDADE LEGISLATIVA RECENTE SOBRE O TEMA}

A compatibilização das matérias previdenciária e trabalhista relacionadas com o tema em debate é assunto que deve integrar a agenda do Congresso Nacional, a fim de que haja, também, compatibilização entre os atos dos próprios Poderes. O STF já deu início ao processo quando reconheceu às uniões homoafetivas o seu caráter de 
entidade familiar. Outros órgãos judiciários caminham nesse mesmo sentido, já tendo sido reconhecido o direito ao salário-maternidade para o genitor homem em casos excepcionais, como do viúvo cuja esposa haja falecido em razão de complicações decorrentes do parto e do pai solteiro - embora haja necessidade de maior abrangência para os demais casos antes tratados.

Importante assinalar que houve um momento de início de atividade legislativa nesse sentido, com o Projeto de Lei do Senado n. ${ }^{\circ}$ 454, de 2008, de autoria do senador Augusto Botelho, que visava a acrescentar o art. 392-B à CLT. ${ }^{13}$

Novamente se percebe que a proteção jurídica recai sobre os direitos do nascituro e da entidade familiar, já que o primeiro período de contato do novo membro com sua família é crucial para que seu desenvolvimento se dê da forma mais positiva possível. Embora a iniciativa seja louvável, observa-se que o texto traz uma discriminação arbitrária dos primeiros filhos em relação aos posteriores, pois somente quando do nascimento daqueles o pai genitor teria direito à estabilidade. $\mathrm{O}$ motivo contido nas razões do projeto dá conta de um provável incentivo à natalidade, acaso estendida a um número ilimitado de filhos.

No atual contexto social e econômico do Brasil, o controle de natalidade independe de intervenção direta estatal. As próprias famílias são compostas por número menor de membros, comparadas com as gerações passadas, que recebiam mais e efetivo auxílio estatal no custeamento dos direitos fundamentais, em especial, os sociais. Cada vez mais o cidadão tem que arcar, além dos altos impostos, com os gastos com educação, saúde e segurança, caso os queira com qualidade minimamente aceitável. Tudo isso faz com que as famílias atuais sejam compostas por menos membros, não sendo crível que um trabalhador vá fazer uso do aumento de natalidade para garantir seu emprego, mesmo porque o tempo de estabilidade seria menor que o tempo necessário para uma gestação seguida da outra.

Aponta-se que essa intervenção estatal de controle de natalidade, no caso, não se mostra plausível ejustificável a fim de que tal distinção fosse estabelecida normativamente. Entende-se não haver respeito ao princípio da igualdade, sem contar que está na contramão do objetivo fundamental da República Federativa do Brasil, de “[...] promover o bem de todos, sem 
preconceitos de origem, raça, sexo, cor, idade e quaisquer outras forma de discriminação", insculpido no inciso IV do art. $3^{\circ}$ da CF/ 88 .

Outro projeto que merece destaque é o Projeto de Lei do Senado n. ${ }^{\circ} 165$, de 2006, que visa a acrescentar dispositivos à Consolidação das Leis do Trabalho nos seguintes termos:

Art. 393-A. Ao empregado é assegurada a licença-paternidade por todo o período da licença-maternidade ou pela parte restante que dela caberia à mãe, em caso de morte, de grave enfermidade, ou do abandono da criança, bem como nos casos de guarda exclusiva do filho pelo pai.

Art. 393-B. O empregado faz jus à licença-paternidade, nos termos do art. 392-A, no caso de adoção de criança, desde que a licença-maternidade não tenha sido requerida.

Ambos os projetos demonstram o sentido correto em podar qualquer tipo de discriminação em relação à figura das crianças e dos próprios pais. No entanto, as mudanças ainda não se concretizaram.

Contudo, não será pela falta de dispositivos legais, ou alterações, como as acima destacadas, que os casos excepcionais abordados devem ficar sem proteção. A questão é perfeitamente solucionável - até que o Legislativo promova as alterações normativas necessárias, adaptadas para as novas relações e situações - com a invocação da hermenêutica constitucional, tratada a seguir.

\section{SALÁRIO-MATERNIDADE E ESTABILIDADE DA GESTANTE PARA HOMENS}

Martin Kriele, citado por Mendes, ${ }^{14}$ afirma:

Não se pode interpretar um texto normativo a não ser colocando-o em relação com os problemas jurídicos concretos (reais ou imaginários), com soluções que se procuram para os casos ocorrentes, porque é somente na sua aplicação aos fatos da vida e na concretização, que assim necessariamente se processa, que se revela completamente o conteúdo significativo de uma norma e ela cumpre sua função de regular situações concretas. 
Está-se tratando, de certa forma, de hermenêutica a ser aplicada para a interpretação de instrumentos normativos infraconstitucionais. Mas a ideia de Martin Kriele é mais que salutar para a hermenêutica constitucional, uma vez que seu texto, propositadamente, traz conteúdo mais abstrato, regulando a ordenação estatal, trazendo princípios estruturantes em seu corpo, de modo a servirem como norte para a formulação de todo o restante do ordenamento jurídico, levando em conta que as constituições possuem caráter de rigidez, donde sua alteração ou reforma exigem procedimento mais dificultoso.

Pode-se pensar, assim, que toda norma jurídica apresenta uma solução que, ao mesmo tempo em que enriquece o arcabouço do instrumento normativo aplicado, resultando em maior alcance aplicativo, com o passar do tempo, pode perder sua eficácia, ou sua própria aplicabilidade, diante do surgimento de outras normas jurídicas de melhor aceitação perante a sociedade, de melhor caráter persuasivo, ou que melhor atenda às necessidades sociais de outro momento de aplicação.

No caso em apreço, as necessidades sociais estão se alterando com as novas formas de constituição das famílias, embora a necessidade de proteção dos filhos, nascituros ou mais velhos, em nada tenha se alterado. Apenas os personagens partícipes desta relação inicial de amor e criação, juntamente com os filhos, é que se alternam.

A CF/88 prevê uma pluralidade de arranjos familiares, estabelece a vedação à distinção entre os filhos havidos ou não da relação do casamento, ou por adoção, além de ter erigido ao âmbito constitucional a proteção à maternidade, o que permite concluir pelo reconhecimento amplo e irrestrito de todos os direitos relativos à proteção dos filhos e de sua família (e o presente estudo não esgota ou taxa tais e quais direitos, apenas traz alguns exemplos). ${ }^{15}$

O art. 226, caput, da CF/88, dispõe que "A família, base da sociedade, tem especial proteção do Estado". Ora, além de reconhecê-la como base da própria sociedade (a base estruturante da própria atividade econômica, portanto), reconhece também o dever do Estado de assegurar proteção especial à instituição. Salienta-se que o constituinte não condicionou ou conceituou família como sendo somente aquela constituída entre um homem e uma mulher, na medida em que previu vários arranjos familiares, como já se expôs linhas atrás. 
Como afirmado, a maternidade não está ligada exclusivamente à figura da mulher, mas, sim, à figura de quem a exerce, podendo ser mulher ou homem. Os próprios arts. 201, II, e 226, § 5 , ambos da CF/88, 16 dão pistas dessa separação, não ordinária e necessária, mas possível em certos casos, entre a maternidade e a própria mulher. Veja-se:

Art. 201. A previdência social será organizada sob a forma de regime geral, de caráter contributivo e de filiação obrigatória, observados critérios que preservem o equilíbrio financeiro e atuarial, e atenderá, nos termos da lei, a:

$[\ldots]$

II - proteção à maternidade, especialmente à gestante [...]

Art. 226. A família, base da sociedade, tem especial proteção do Estado [...]

$\S 5^{\circ}$ Os direitos e deveres referentes à sociedade conjugal são exercidos igualmente pelo homem e pela mulher.

$\mathrm{O}$ art. $5^{\circ}$, I, da CF/88 é expresso ao afirmar que homens e mulheres são iguais em direitos e obrigações, nos seus termos. $\mathrm{O}$ processo de constitucionalização das disciplinas jurídicas permite tanto à doutrina quanto à jurisprudência buscar fundamentação para apreciar questão desse quilate. Melhor dizendo, é dever do julgador encontrar e apresentar fundamentos para tanto, principalmente quando expresso na Constituição o dever de dar proteção especial à família, base da sociedade.

A CF/88 ainda determina, no art. 227, que o dever de assegurar à criança, ao adolescente e ao jovem todos os direitos nela contidos é da família, da sociedade e do Estado, com absoluta prioridade. É prioridade que o Estado dê garantia aos pais homens, nos casos excepcionais aqui tratados, para que tenham tranquilidade em relação ao emprego, de modo a estabelecer o primeiro contato vital com seus filhos, biológicos ou adotados, independentemente da idade, da melhor forma possível e com a maior participação possível.

Assim, observa-se que a legislação que confere o direito à estabilidade à gestante e licença-maternidade à mãe biológica e à mãe adotiva 
é perfeitamente aplicável, em sua totalidade, aos casos excepcionais que se expôs, sem necessidade de manobras ou malabarismos jurídicos.

Nesse ponto, interessante apresentar o que já vem sendo concedido administrativamente em relação ao salário-maternidade, valendo destacar decisão proferida pelo Conselho Superior da Justiça do Trabalho (CSJT), em 27-3-2009, no processo CJT-150/2008-895-15-00.0, que conferiu o direito à licença-maternidade a um servidor na condição de pai solteiro em decorrência da adoção de uma criança. ${ }^{17}$

Também, a título de ilustração, destaca-se que a Caixa Econômica Federal, conforme notícia extraída do seu sítio oficial, já vem concedendo, desde 2009, licença-maternidade aos pais solteiros e casais homoafetivos que adotarem criança de zero a oito anos. ${ }^{18}$

Importante destacar que não se está a tratar da licença-paternidade, prevista no $\S 1^{\circ}$ do art. 10 do Ato das Disposições Constitucionais Transitórias (ADCT), concedida pelo prazo de cinco dias ao trabalhador homem por ocasião do nascimento de filho ou adoção de criança. Assim, é necessário que se proceda a uma exegese razoável dos dispositivos legais, de modo que não se conceba fruição de períodos de licenças acrescidos, pois, sem dúvida, esse não é o escopo da norma jurídica, na medida em que a licença maternidade é que deve ser concedida ao genitor nos casos aqui tratados. ${ }^{19}$

Em todos os casos relacionados com a concessão de licença-maternidade para o genitor homem há menção expressa sobre a necessidade de proteção da figura da criança, inclusive no caso de adoção, independentemente da idade desta.

Da mesma forma, a garantia provisória de emprego conferida à empregada gestante, conforme previsão do art. 10, II, b, do ADCT, deve ser igualmente assegurada aos homens em todos os casos excepcionais abordados.

Embora haja quem defenda que a referida garantia de emprego foi conferida apenas à empregada gestante, não tendo ela sido estendida às empregadas adotantes, essa não foi a intenção do constituinte, uma vez que tal afirmação representa imprimir distinção gritantemente discriminatória, vedada pela $\mathrm{CF} / 88$, nos termos do $\S 6^{\circ}$ do art. $227 .{ }^{20}$ 
Depreende-se que, mesmo sem as alterações legislativas que implementassem expressamente o direito à estabilidade para os casos excepcionais aqui tratados, os direitos em debate podem ser assegurados. Eventual alteração legislativa que conferisse expressamente referido direito apenas iria pacificar a questão, ainda controvertida, eliminando a situação de insegurança jurídica existente hoje. Como asseverado, a interpretação sistemática da CF/88 confere ao genitor homem, nas hipóteses aqui abordadas, além da licença-maternidade, a estabilidade no emprego.

Caso a esposa venha a falecer por complicações decorrentes do parto, a estabilidade antes conferida à mulher passará automaticamente ao homem, desde a data do óbito, pelo que lhe restar.

Na hipótese do genitor ou futuro genitor, quando único provedor da renda familiar, a mencionada garantia surge a partir da confirmação da gravidez, até cinco meses após o parto. O próprio texto do projeto de lei arquivado antes de sua aprovação pode ser aproveitado, de modo que o período de estabilidade - para o caso de genitores ou futuros genitores, quando únicos provedores de renda familiar - tenha início com a confirmação da gravidez e até cinco meses após o parto. Os requisitos e prazos do salário-maternidade também devem ser os mesmos nesse caso.

Nas famílias monoparentais masculinas e nas uniões homoafetivas masculinas, na medida em que a prole pode decorrer de reprodução assistida $^{21}$ ou da adoção, o genitor também possui direito à garantia de emprego. Contudo, no segundo caso, tendo em vista que existem dois genitores, à apenas um deles será conferido o referido direito, devendo o casal escolher qual dos pais irá gozar a licença-maternidade e a garantia de emprego, mediante de documentação apresentada aos respectivos empregadores, bem como à Previdência Social. O outro genitor gozará licença-paternidade.

Para o casal homoafetivo que adotar uma criança, deve-se levar em conta o disposto no Estatuto da Criança e do Adolescente (ECA), Lei n. ${ }^{\circ} 8.069$, de 13 de julho de 1990, cujo art. 46 estabelece que a adoção é precedida de período de convivência com a criança ou adolescente, pelo prazo que o juiz fixar, dadas as peculiaridades de cada caso. Esse período de convivência pode ser dispensado para o caso de o 
adotando já estar sob a tutela ou guarda judicial do adotante durante tempo suficiente que permita avaliar a conveniência da constituição do vínculo. $\mathrm{O}$ art. 47 , por sua vez, estabelece que o vínculo da adoção é confirmado com a sentença judicial.

Assim, no caso de adoção com estipulação judicial de período de convivência, a estabilidade tem como marco inicial o prazo determinado pelo juiz, estendendo até cinco meses após a sentença judicial constitutiva do ato da adoção transitada julgado. Para o caso de adoção em que o período de convivência seja dispensado pela existência de guarda judicial, o marco inicial deve ser a data do deferimento judicial da guarda, que pode ser liminar ou incidental, tanto em processo de adoção, quanto de tutela, estendendo-se até cinco meses após a sentença judicial constitutiva transitada em julgado.

Para finalizar, assinale-se que o Código do Trabalho de Portugal prevê a licença-paternidade de cinco dias, porém, em casos excepcionais, é conferido ao homem igual período ao da mulher, caso esta faleça após o parto ou fique incapaz física ou psiquicamente ou, ainda, por decisão conjunta dos pais. ${ }^{22}$

\section{TUTELA DE DIREITOS}

A posição aqui sustentada é no sentido de que o genitor homem, nas hipóteses de falecimento da esposa em razão de complicações decorrentes do parto, de pai solteiro (família monoparental), de união homoafetiva masculina e de genitor ou futuro genitor quando único provedor da renda familiar, já tem o seu direito à licença-maternidade e à estabilidade garantidas pelo ordenamento jurídico vigente, mesmo sem qualquer alteração legislativa.

Saliente-se que eventual alteração legislativa que estabeleça expressamente referidos direitos já garantidos pela interpretação sistemática do texto constitucional que aqui se expôs apenas iria pacificar a questão, ainda controvertida, sanando qualquer controvérsia e insegurança jurídica.

Assim, é perfeitamente possível que o trabalhador requeira ao Instituto Nacional do Seguro Social (INSS) o benefício previdenciário 
do salário-maternidade, e faça valer o seu direito à estabilidade junto ao seu empregador.

Contudo, tendo em vista que essa leitura ainda se mostra controvertida, é possível que lhe sejam negados os referidos direitos, hipótese em que o trabalhador pode se valer de mecanismos judiciais diversos, a exemplo de ação ordinária com pedido de tutela antecipada para implantação do benefício previdenciário (em face do INSS) e de reclamação trabalhista com pedido de tutela antecipada para ser reintegrado no emprego, uma vez que é detentor de estabilidade (em face do empregador).

Os sindicatos, aos quais a CF/88 conferiu ampla legitimação extraordinária para defesa da categoria, nos termos do inciso III, do art. $8^{\circ}$, também podem se valer de ação individual ou coletiva para assegurar referidos direitos. Igual legitimidade detém o Ministério Público do Trabalho, que pode impetrar ação civil pública, nos termos dos arts. 127 e 129, ambos da CF/ 88 .

\section{CONCLUSÃO}

Ao longo do trabalho, asseverou-se que, dentro da cultura que dominava a sociedade brasileira, o papel de educar os filhos sempre coube à mulher. A função destinada ao homem dentro de uma sociedade fundada num modelo patriarcal sempre foi o de mantenedor da casa. Essa manutenção estaria ligada apenas aos aspectos financeiros, podendo o homem ficar alheio às exigências do cotidiano de afetividade e educação dos filhos, na medida em que tais tarefas pertenciam apenas à mulher.

Contudo, esse panorama tem sofrido transformações nos últimos tempos. A família deixou de ser formada única e exclusivamente pelo indissolúvel vínculo matrimonial entre o homem e a mulher. Aliás, o próprio matrimônio deixou de ser indissolúvel - com o surgimento do divórcio - e deixou também de ser exclusividade das relações heteroafetivas - a partir do reconhecimento do caráter de entidade familiar das uniões homoafetivas. Assim, observa-se que uma família pode ser formada por meio do casamento e da união estável, sejam eles héteros, sejam homoafetivos, bem como podem constituir uma família monoparental. 
Embora exista uma proximidade maior da criança com a mãe, em detrimento do papel do pai, o que ocorre não apenas por questões biológicas, mas também culturais, a maternidade deixou de ser exercida com exclusividade pela mulher após a sua inserção no mercado de trabalho e a partir do surgimento de novos arranjos familiares.

A licença-maternidade, conforme se expôs, não é um direito destinado exclusivamente à mulher; também é um direito da criança. Aliás, entende-se que a licença-maternidade nos dias atuais tem como escopo principal a proteção da criança, não podendo mais ser vista como um período destinado apenas à recuperação da mãe, em consonância com a doutrina da proteção integral adotada pela CF/ 88 (art. 227) e pelo ECA $\left(\operatorname{art.} 1^{\circ}\right)$, devendo sempre ser considerado o melhor interesse do menor.

Observa-se que, em regra, a licença-maternidade deve ser assegurada à mulher. Contudo, em determinadas hipóteses, ela será gozada pelo homem. ${ }^{23}$ Tal ocorrerá nos casos em que a genitora venha a óbito por complicações decorrentes do parto, nas famílias monoparentais masculinas, ${ }^{24}$ nas uniões homoafetivas masculinas e também nos casos em que o genitor ou futuro genitor for o único provedor da renda familiar. Em todos os casos com a interpretação sistemática do texto constitucional.

Entende-se que, nas hipóteses aqui tratadas, não somente o direito à licença-maternidade deve ser garantido ao genitor homem, ao qual deve ser assegurada também a garantia de emprego prevista no art. 10, II, $b$, do ADCT.

A compatibilização das matérias previdenciária e trabalhista relacionadas com o tema em debate é assunto que deve integrar a agenda do Congresso Nacional, a fim de que haja, também, compatibilização entre os atos dos próprios Poderes. O STF já deu início ao processo quando reconheceu às uniões homoafetivas o seu caráter de entidade familiar. Outros órgãos judiciários caminham nesse mesmo sentido, já tendo sido reconhecido o direito ao salário-maternidade para o genitor homem em casos excepcionais, como do viúvo cuja esposa haja falecido em razão de complicações decorrentes do parto e do pai solteiro - embora haja necessidade de maior abrangência para os demais casos aqui tratados. 


\section{A extensão dos direitos destacados - não taxados - no trabalho} para os genitores homens, o que antes se relacionava apenas com a figura da mulher, com referência aos filhos, é a melhor maneira de reforçar a constante dinâmica social que exige, cada vez mais, a participação do homem na criação assistida de seus filhos, biológicos ou adotados, independentemente da idade. Essa é a vontade do constituinte ao garantir que "[...] homens e mulheres são iguais em direitos e obrigações, nos termos desta Constituição" (art. $5^{\circ}$, I, da CF/88). Não assegurar a estabilidade da gestante e a licença-maternidade nos casos tratados no trabalho corresponde ao enfraquecimento da força normativa da Constituição.

\section{NOTAS}

1 HORVAT JÚNIOR, Miguel. Direito previdenciário. 5. ed. São Paulo: Quartier Latin, 2005.

2 V. g. arts. 1.514, 1.535 e 1.565. OSTF afastou as expressões utilizadas pelo CC, permitindo o reconhecimento da união de pessoas do mesmo sexo, adiante tratado no presente trabalho.

3 Pela Lei n..$^{\circ}$ 6.136/1974, embora já subscrita pelo país no Decreto de Promulgação n. ${ }^{\circ}$ $58.820 / 1966$.

4 Foi noticiada a concessão pela $6^{\text {a }}$ Vara Federal de Brasília/DF de licença-maternidade a genitor cuja esposa havia falecido 34 dias após ter dado à luz o filho do casal, em razão de complicações decorrentes do parto. (Disponível em: <http:/ / noticias.uol.com.br/cotidiano/ ultimas-noticias / 2012/02/13/viuvo-ganha-na-justica-direito-a-licenca-maternidade-de-seis-meses-para-cuidar-do-filho.htm>. Acesso em: 15 jul. 2012).

5 A Convenção n. ${ }^{\circ} 3$ foi ratificada pelo Brasil em 27 de março de 1934 e promulgada pelo Decreto n. ${ }^{\circ} 423$, de 12 de novembro de 1935. Posteriormente, em 18 de dezembro de 1962, a referida Convenção foi denunciada pelo Brasil, em face de sua revisão pela OIT, no ano de 1952.

6 Nesse sentido, é a Orientação Jurisprudencial n. ${ }^{\circ} 44$ da SDI-1 do TST.

$7 \quad$ Arts. 71 a 73 da Lei n. $^{\circ} 8.213 / 91$.

8 Nesse sentido: Horvath Júnior, (2005, p. 232).

9 Havia uma antinomia entre o art. 392-A da CLT e o art. 71-A da Lei n. ${ }^{\circ}$ 8.213/91, já que o primeiro passou a prever, na redação dada pela Lei $n^{\circ}$. 12.010/02, o direito à licença-maternidade de 120 dias nos casos de adoção, independentemente da idade do adotado, enquanto o segundo continuava prevendo o direito ao salário-maternidade de forma escalonada, a depender da idade do adotado. Essa antinomia foi corrigida primeiramente pelo Poder Judiciário no julgamento da Ação Civil Pública n. ${ }^{\circ}$ 5019632-23.2011.404.7200, cujo trâmite se deu perante a $1^{\mathrm{a}}$ Vara Federal de Florianópolis/SC. Mais recentemente, com a edição da Lei n. ${ }^{\circ} 12.873$, de 24 de outubro de 2013, essa antinomia deixou de existir, já que foi dada nova redação ao art. 71-A da Lei n. ${ }^{\circ} 8.213 / 91$, que passou a prever o direito ao salário-maternidade de 120 dias nos casos de adoção, independentemente da idade do adotado.

10 Ver Ação Civil Pública n. ${ }^{\circ}$ 5019632-23.2011.404.7200, da $1^{\text {a }}$ Vara Federal de Florianópolis/ SC (Disponível em: <http://previdencia.gov.br/vejaNoticia.php?id=46605\#destaque>. Acesso em: 6 jul. 2012).

11 “O condicionamento social certamente que existe; mas explicará as diferenças entre os sexos? Quando muito, não passa de uma explicação incompleta. Precisamos de saber *que motivos* terá a nossa sociedade -- e não apenas a nossa, mas praticamente toda e qualquer sociedade humana -- para moldar as crianças desta maneira. Uma resposta popular é a de que nas primeiras sociedades, mais simples, cabiam aos sexos papéis diferentes porque as mulheres tinham de amamentar as crianças durante o longo período anterior ao desmame. Por esse motivo, as mulheres ficavam mais perto de casa, enquanto os homens 
saíam para caçar. Como a força física e a agressividade eram as formas supremas de poder nessas sociedades simples, os homens tornaram-se dominantes. Os papéis sexuais que hoje existem, de acordo com essa perspectiva, constituem uma herança dessas circunstâncias mais simples, um legado que se tornou obsoleto a partir do momento em que a tecnologia tornou possível a uma pessoa fraca utilizar uma grua para içar 50 toneladas ou disparar um míssil que mata milhões de pessoas. Tão-pouco as mulheres têm de ficar presas ao lar e às crianças da forma como acontecia antigamente, visto uma mulher poder hoje conciliar a maternidade com uma carreira profissional" (SINGER, 1993, p. 26).

12 Diz-se no mínimo igual, pois a mulher, além de sair do lar para trabalhar, ainda hoje possui uma segunda jornada, consistente em organizar o lar e prestar cuidados aos filhos, o que ainda merece maior atenção pelo movimento feminista, para que haja distribuição entre os genitores das responsabilidades relativas a essa segunda jornada, que se inicia quando do retorno ao lar, o que é a proposta do presente trabalho, inclusive.

13 Referido dispositivo, caso houvesse sido aprovado, teria o seguinte texto: “Art. 392-B. É vedada a dispensa imotivada de genitores e futuros genitores empregados, únicos provedores de renda da família, desde a confirmação da gravidez até seis meses após o parto; $\S 1^{\circ}$ Para fazer jus ao benefício previsto neste artigo o empregado deverá contar com pelo menos um ano de trabalho na empresa e comunicar ao empregador, mediante atestado médico, a confirmação da gravidez e a ocorrência do nascimento do filho, antecipado ou não, bem como uma eventual interrupção da gravidez. $\S 2^{\circ} \mathrm{O}$ benefício previsto neste artigo será anotado na Carteira de Trabalho e Previdência Social - CTPS e somente será concedido em relação aos primeiros dois filhos do genitor". Referido projeto tramitou pela Comissão de Assuntos Sociais do Senado, com aprovação para votação, conforme relatório do senador Geraldo Mesquita Júnior, em 24-3-2010. Contudo, em 4-2-2011, foi determinado seu arquivamento, nos termos do art. 332 do Regimento Interno do Senado Federal, em razão de seu autor não estar mais no mandato no início daquela legislatura.

14 MENDES, Gilmar Ferreira; COELHO, Inocêncio Martires; BRANCO, Paulo Gustavo Gonet. Curso de direito constitucional. 5. ed. São Paulo: Saraiva, 2010. p. 109.

15 “ESTABILIDADE DA GESTANTE, RENÚNCIA OU TRANSAÇÂO DE DIREITOS CONSTITUCIONAIS. IMPOSSIBILIDADE. Nos termos do art. 10, II, “b”, do ADCT, a proteção à maternidade foi erigida à hierarquia constitucional, pois retirou do âmbito do direito potestativo do empregador a possibilidade de despedir arbitrariamente a empregada em estado gravídico. Portanto, a teor do art. $9^{\circ}$, da CLT, torna-se nula de pleno direito a cláusula que estabelece a possibilidade de renúncia ou transação, pela gestante, das garantias referentes à manutenção do emprego e salário" (Orientação Jurisprudencial n. ${ }^{\circ} 30$ da Seção de Dissídios Coletivos do TST).

16 O óbice das expressões contidas nos arts. 1.723 do CC, e $226, \S 3^{\circ}$, da CF/ 88 , para o reconhecimento da união estável entre pessoas do mesmo sexo foi afastado pelo STF, quando do julgamento conjunto da ADPF 132 e da ADI 4277, devendo o afastamento se estender às expressões contidas no $\S 5^{\circ}$ do mesmo dispositivo constitucional.

17 Destacam-se, inclusive, alguns pontos da referida decisão: “[...] o servidor público, independente do gênero e do estado civil merece tratamento isonômico, por ser medida que atende ao princípio da proteção ao menor, consagrado na Constituição Federal e no estatuto da criança e do adolescente [sic]. [...] Aliás, eventual conclusão no sentido de se obstaculizar o direito do servidor implicaria, a meu ver, manifesta ofensa ao princípio constitucional da isonomia, além de consagração de tese que, certamente, não conseguiu acompanhar a evolução da nossa sociedade".

18 Disponível em: <http://www1.caixa.gov.br/imprensa/imprensa_release. asp?codigo=6609712>. Acesso em: 14 jul. 2012.

19 Por essa razão é que se preferiu empregar a terminologia licença-maternidade e estabilidade da gestante, mesmo quando esses direitos são gozados por um homem, a fim de que não haja confusão com a licença-paternidade prevista no $\S 1^{\circ}$ do art. 10 do ADCT.

20 Nesse sentido, ver GARCIA, Gustavo Filipe Barbosa. Curso de direito do trabalho. 6. ed. rev., atual. e ampl. Rio de Janeiro: Forense, 2012. p. 1022-1023. 
21 Embora ainda não seja muito frequente, em razão dos elevados custos, observa-se ser possível a reprodução assistida, por meio da fertilização in vitro, inclusive utilizando-se de uma barriga solidária. Há notícia de casais homoafetivos masculinos e também de famílias monoparentais masculinas que têm se utilizado desses meios para gerar sua prole. Caso de grande repercussão na mídia foi o do cantor Ricky Martin que teve filhos gêmeos, nascidos no ano de 2008, gerados em barriga "de aluguel", como é popularmente conhecida. Mais recentemente, conforme notícia extraída do sítio do Tribunal de Justiça do Estado de São Paulo, duas mulheres que vivem em união estável homoafetiva ajuizaram ação declaratória de filiação pleiteando a lavratura de assento de nascimento dos filhos gêmeos, frutos dos óvulos de uma delas, fertilizados in vitro com o sêmen de um doador anônimo e, posteriormente, implantados no ventre da outra, que se tornou gestante e genitora. A averbação nos assentos de nascimento dos gêmeos para constar na certidão de nascimento o nome das duas mães foi autorizada em 26-7-2012 pela $2^{\text {a }}$ Vara de Registros Públicos da Capital. Observa-se que, neste caso concreto, como deve efetivamente ocorrer nessas situações, foi reconhecida a filiação originária, e não a decorrente da adoção (Disponível em: <http://www.tjsp.jus.br/Institucional/CanaisComunicacao/ Noticias/Noticia.aspx?Id=15036>. Acesso em: 30 jul. 2012).

22 Art. 36: "1. O pai tem direito a uma licença por paternidade de cinco dias úteis, seguidos ou intercalados, que são obrigatoriamente gozados no primeiro mês a seguir ao nascimento do filho. 2. O pai tem ainda direito a licença, por período de duração igual àquele que a mãe teria direito nos termos do artigo anterior [que trata da licença por maternidade, de 120 dias], ou ao remanescente daquele período caso a mãe já tenha gozado alguns dias de licença, nos seguintes casos: a) Incapacidade física ou psíquica da mãe, e enquanto esta se mantiver; b) Morte da mãe; c) Decisão conjunta dos pais. 3. No caso previsto na alínea b) do número anterior o período mínimo de licença assegurado ao pai é de 30 dias. 4. A morte ou incapacidade física ou psíquica da mãe não trabalhadora durante o período de 120 dias imediatamente a seguir ao parto confere ao pai os direitos previstos nos n ${ }^{\circ} 2 \mathrm{e} 3^{\prime \prime}$ (grifo nosso)

23 Importante ressaltar que não se está a tratar da licença-paternidade prevista no $\S 1^{\circ}$ do artigo 10 do ADCT, mas da própria licença-maternidade.

24 Nesse sentido, ver decisão proferida pelo desembargador-presidente do Tribunal de Justiça de Pernambuco, em 22-8-2011, que conferiu a um ocupante de cargo em comissão solteiro o direito à licença-maternidade em razão de ter adotado uma criança, a qual "[...] será imprescindível aos cuidados essenciais e à boa adaptação da criança" (Processo n. ․ 1694/ 2011 (RP n. $\left.{ }^{\circ} 104721 / 2011\right)$, Diário da Justiça Eletrônico do TJPE, ano III edição no 157 /2011, pág. 4 a 6, data da publicação 25-8-2011).

\title{
REFERÊNCIAS
}

\author{
BOSSA, Sonia. Direito do trabalho da mulher no contexto social \\ brasileiro e medidas antidiscriminatórias. São Paulo: Editora Oliveira \\ Mendes, 1998.
}

\author{
HORVARTH JÚNIOR, Miguel. Direito previdenciário. 5. ed. São \\ Paulo: Quartier Latin, 2005.
}
LUHMANN, Niklas. Legitimação pelo procedimento. Tradução de Maria da Conceição Côrte Real. Brasília: Editora Universidade de Brasília, 1980.


MENDES, Gilmar Ferreira; COELHO; Inocencio Martires; BRANCO, Paulo Gustavo Gonet. Curso de direito constitucional. 5. ed. São Paulo: Saraiva, 2010.

SINGER, Peter. Ética prática: Peter Singer. Tradução de Álvaro Augusto Fernandes. [s.1.]: Tipografia Lugo Ltda., 1993.

Artigo recebido em: 30-8-2012

Aprovado em: 19-12-2013

\section{Assis Moreira Silva Júnior}

Mestre em Direito Centro Universitário de Bauru (ITE); especialista em Jurisdição Constitucional e Tutela Jurisdicional dos Direitos Fundamentais pela Universitá di Pisa, Itália. Advogado; conciliador/mediador do TJSP e do TRF da $3^{\text {a }}$ Região; professor universitário; membro efetivo da Comissão da Diversidade Sexual e Combate à Homofobia da OAB - Seção São Paulo; coordenador da Comissão da Diversidade Sexual da OAB/Bauru; presidente da Comissão de Direito Homoafetivo e Diversidade Sexual do IBDFAM em Bauru.

Rua Afonso Pena, 5-3. Jardim Bela Vista. CEP 17060250 - Bauru - SP. E-mail: junior_ite@yahoo.com.br

\section{Luís Fernando Severino}

Mestre em Sistema Constitucional de Garantia de Direitos pela Instituição Toledo de Ensino (ITE); especialista em Direito do Trabalho e Processual do Trabalho pela Escola Paulista de Direito (EPD); especialista em Direito Previdenciário pelo Centro Universitário Toledo (UNITOLEDO); especialista em Direito Ambiental pela Universidade Metodista de Piracicaba (UNIMEP); advogado.

Sindicatos dos metalurgicos de Piracicaba.

rua prudente de Moraes, 914. CEP 13400315 Piracicaba - SP.

E-mail: feradvpira@yahoo.com.br 